THURSDAY, JANUARY 2, I9I9.

\section{INTERNATIONAL ORGANISATION OF} SCIENCE.

THE formation of a conside able number of international organisations for the promotion of scientific observation and research is the result of the recognition of the fact that international co-operation is highly desirable in all directions, and is even indispensable in many cases.

A memorandum prepared by the Royal Society early in 1918 gives a list of about seventy-five such associations of scientific workers, and there are many more. The Royal Society list is divided into five groups, which include such subjects as standards of weight and measure, atomic weights and physico-chemical constants, problems in geodesy, seismology, meteorology, and exploration of the sea, the chart of the heavens, an international chart of the world, and the cataloguing of scientific literature. Eighteen congresses which meet periodically are concerned with various departments of pure and applied science, from mathematics to medical radiology, while the International Associctions of Academies aims at unifying international work and the avoidance of duplication. There are many other associations, some of which have been long in operation, while others have been called into existence by modern developments, as, for instance, in relation to aviation.

Since the beginning of the war it has become increasingly obvious that direct communication between the Allied Powers (including the United States) and the Central European Powers was no longer possible. Neither did it seem probable that the Allies would consent to personal communication with the German peoples, even after the cessation of hostilities, until the latter had adopted an entirely new attitude towards the rest of the world. Of this change of mind and heart there is but small indication at present, and consequently the time when cordial assistance and co-operation can be mutually exchanged between the Allied Powers and the German-speaking peoples seems indefinitely postponed. The problem, then, is, What can be done with these international organisations? They must be freed from German membership and influence, and to accomplish this either the Germans must be excluded or new and independent associations must be formed by the Allies, together with such neutral Powers as, after deliberation, choose to dissociate themselves from Teutonic combinations. The latter appeared to be the only practicable course, and at the conference recently held in Paris, of which an account NO. 2566, VOL. IO2] was given in NATuRE of December 26, resolutions were carried affirming the necessity for the formation of new international associations in place of the old. These associations will provide for the development of international action in relation to all the subjects mentioned above, but leaving to diplomatic agency the merely administrative relations between public services, such as those regulating navigation, railways, telegraphs, weather reports, etc.

The representatives of science in the United States propose to go further. An executive order by President Wilson under date May II, 1918, refers to the National Research Council which was called into existence in 1916 by the U.S.A. National Academy of Sciences, with an eye especially to national requirements in time of war. The work of this council having proved so valuable, it is now constituted on a permanent basis, with duties specified in a series of paragraphs. These duties include not merely the task of bringing into co-operation for national purposes the industrial, naval, and military agencies. The council is expected to stimulate research in every department of science, to survey the larger possibilities of science, to formulate comprehensive projects of research, and to develop effective means of utilising the scientific and technical resources of the country for dealing with these projects. Needless to add, co-operation, national and international, is to be freely invoked.

At the Inter-Allied Conference held in London in October, and at the later Conference in Paris, the idea developed into the proposal not only to form a National Research Council in each country, but the meeting itself assumed provisionally the title of "The International Research Council," with an executive committee of five members and an administrative bureau to be established in London. The president of the new body is M. E. Picard, one of the permanent secretaries of the French Academy of Sciences, the other members bcing Prof. G. E. Hale, representing the United States; Prof. Volterra, representing the Accademia dei Lincei of Rome; Major Lecointe, representing Belgium; and Prof. Arthur Schuster, representing the Royal Society. It will be the duty of this executive committee to work out the details of the organisation to be ultimately adopted, and to submit its proposals to the various bodies concerned.

Among the subjects discussed at the conference in Paris were the proposals, already under consideration by many universities, for adding to the facilities offered to students of one nationality by teaching institutions in Allied countries. Questions relating to bibliography, the publication of 
abstracts of scientific memoirs, and the cataloguing of scientific papers were also considered, as well as the serious international problem relating to patent laws in different countries.

Anyone who has followed the course of events in the scientific world during the last twenty years or more will perceive that subjects of this kind have not been neglected, and that many preparatory steps have been taken, but it is also obvious that in regard to nearly all these matters we have been drifting gradually towards a chaos more and more confounded. The establishment of the system of international councils seems to be the only hope of ultimately arriving at some state of order. Readers of NATURE have been informed of the establishment in this country of the Committee of the Privy Council for Scientific and Industrial Research, and the existence of several subsidiary boards, such as those for fuel research, food investigation, and several others, with related advisory boards, as well as the National Physical Laboratory. But the co-ordination of the whole remains to be accomplished, and, so far as this country is concerned, movement in this direction is not yct in view, though it has long been urged by the British Science Guild and in these columns. The British Government is too fond of leaving things at the disposal of its permanent officials in Whitehall, who, however able they may be as officials, are in nearly all cases laymen in respect to questions involving scientific knowledge and experience. The President of the United States proceeds on a different principle in placing the whole task of organisation in the hands of the National Academy of Sciences, with power to select such representatives of the Government as are required for administrative work.

Perhaps it will be useful to add a few remarks on the subjects which are intended for investigation by these National Research Councils. Broadly speaking, there is no limit; all Naturc is to be reviewed, experimented on, sounded, tested. It requires no great foresight to perccive that, on the whole, results which are expected to be immediately useful will especially be looked for by the expectant world outside. Now research may be of two kinds, one of which falls easily within the province of co-operative inquiry : the investigation of the origin, properties, and qualities of natural materials of all kinds-coal and other minerals, fibres, woods, dyes, medicinal agents, and the cultivation of medicinal plants; investigation of problems in connection with agriculture, the strength of metals, corrosion or rusting of metals and decay of all kinds of materials, such as timber, cement, and buildingNO. 2566 , VOL. IO2 stone. To such inquiries may be added the accurate determination of many physical constants which are at present imperfectly known, such as melting-points, boiling-points, specific heats, or electrical conductivities, all of which may come to be very valuable, or even indispensable, in the improvements to be made in machinery and engines of all kinds.

Here are fields wide enough and full enough to occupy whole armies of workers for generations. to come, and they afford examples in every direction where co-operative labour is likely to accomplish that which might defy altogether the unassisted effort of the individual worker. It is also quite possible that in the resulting enlarged and more accurate view of natural materials and resources phenomena will present themselves among which the eye of genius may perceive the way to generalisations of incalculable importance. It was the careful and accurate estimation of the densities of gases by Rayleigh which led to the discovery. of the argon series of gases. It was the study of the crystalline form of the tartrates which led l'asteur by successive steps to discoveries which resulted later in the development of the entire department of science known as stereo-chemistry. For ages the fact has becn known that certain substances--e.g. calcined oyster-shells -exhibit a feeble luminosity; but it was the systematic study of phosphorescent phenomena by Becquerel which led, in the hands of the Curies, to the discovery of radio-activity, with all its amazing consequences.

Similarly, it may be expected that research on a large scale will lead to the observation of phenomena which the international worker may not be able to interpret, but which will remain for study by the exceptionally endowed worker, who, like the poet, invokes the aid of imagination, while at the same time he has the skill, patience, and wide knowledge which enable him to derive assistance from analogous cases in departments other than his own. This kind of specialist is not to be found every day, and will not be developed even by co-operation on international lines. This is the natural senius who appears, like a Newton or a Faraday, once in a century or two. Individual freedom in fields open to research must not be controlled or impeded by schemes of organisation, nor must the public inquire too closely what is the use of this or that discovery. In course of time the study and contemplation of natural phenomena in the light of more extended knowledge will come to be acknowledged as the source of a pure joy and satisfaction to many, as art is a recognised source of happiness to others. This view of the matter should be kept sedulously in mind by every teacher. 